\section{Filling the gap}

\section{By Steve Edelson, Executive Editor}

Although a growing number of universities and research centers are taking steps to incubate translatable early-stage research, ${ }^{1,2}$ the vast majority of institutions have yet to address the gap that exists between their discoveries and the further development required before a biotech or pharma gets interested. U.K.-based TPP Global Development Ltd. is hoping to play the role of middleman for such institutions.

TPP raised $£ 9.6$ million (\$13.9 million) last month in a series A round with Scottish Enterprise and other investors. The company plans to use the proceeds to in-license early preclinical

\section{"Deal terms have gone up for preclinical compounds." \\ -Peter Trill, TPP Global Development Ltd.}

licensing anything that hasn't been put into animals. The company sees potential in picking programs at even earlier stages along the value chain, including newly identified targets for which no modulators have yet been generated. Indeed, the majority of the company's in-licensing sweet spot covers the funding gap between new targets and optimized leads.

"Deal terms have gone up for preclinical compounds, and there's an opportunity now for a company to come in, source IP from universities and research institutes and develop that IP either in its own labs-or in our case CROs-or with the original inventor and then out-license those drug programs in late-stage preclinical development," Trill told SciBX.

TPP is hiring a $10-15$ person staff to identify projects; the majority will be Ph.D. scientists in the company's focus areas. The company plans programs, mainly from universities and research to cast its net for assets by scouring scientific meetings and reaching out to technology transfer offices.

"Different universities have different models even amongst their tech transfer offices," noted Trill. "But on the whole I've been really impressed institutes, fund the necessary development work at the originating organizations or at contract research organizations (CROs) and then out-license the programs to companies or spin out the assets.

TPP was founded last year and is focused on nervous system disorders, immunology/inflammation and cancer. The company initially will in-license assets from institutions in the U.K., Europe and the U.S. and later plans to extend its reach to Asia.

"Having been a healthcare investor, as have my business partners, I recognize that industry dynamics have changed over the last decade. Ten years ago, large-cap companies were looking at late-stage in-licensing opportunities in Phase II or III testing. They also were focused on pumping money into their own preclinical R\&D and discovery to innovate in-house," said TPP CFO Peter Trill. "Now they are shifting their strategy and are more dependent on in-licensing and doing so at an earlier and earlier stage."

The key for TPP, said Trill, is that biotech and pharma companies still draw a line at the preclinical stage, generally shying away from in- with the offices that we've engaged with-they're all a designated point of contact where you walk in and there's effectively a shop window of assets that are available for licensing."

Trill wouldn't disclose how many projects TPP plans to bring under its roof and said it's too early to discuss potential deal terms.

Picking projects will be key, said Lita Nelsen, director of the Technology Licensing Office at the Massachusetts Institute of Technology.

"Like most university-stage licensing, it's a lottery game-one big winner will pay for it all," she said.

Edelson, S. SciBX 3(22); doi:10.1038/scibx.2010.664

Published online June 3, 2010

\section{REFERENCES}

1. Edelson, S. SciBX 2(20); doi:10.1038/scibx.2009.815

2. Osherovich, L. SciBX 3(15); doi:10.1038/scibx.2010.455

COMPANIES AND INSTITUTIONS MENTIONED

Massachusetts Institute of Technology, Cambridge, Mass.

TPP Global Development Ltd., Edinburgh, U.K. 